\title{
Effect of a retinoid $X$ receptor partial agonist on airway inflammation and hyperresponsiveness in a murine model of asthma
}

Utako Fujii ${ }^{1}$, Nobuaki Miyahara ${ }^{1}$, Akihiko Taniguchi ${ }^{1}$, Naohiro Oda ${ }^{1}$, Daisuke Morichika', Etsuko Murakami ${ }^{1}$, Hikari Nakayama', Koichi Waseda', Mikio Kataoka', Hiroki Kakuta², Mitsune Tanimoto ${ }^{1}$ and Arihiko Kanehiro ${ }^{1 *}$

\begin{abstract}
Background: Retinoid X receptors (RXRs) are members of the nuclear receptor (NR) superfamily that mediate signaling by 9-cis retinoic acid, a vitamin A (retinol) derivative. RXRs play key roles not only as homodimers but also as heterodimeric partners - e.g., retinoic acid receptors (RARs), vitamin D receptors (VDRs), liver X receptors (LXRs), and peroxisome proliferator-activated receptors (PPARs). The NR family was recently associated with allergic diseases, but the role of RXRs in allergen-induced airway responses is not well defined. The goal of this study is to elucidate the role of RXRs in asthma pathogenesis and the potency of RXR partial agonist in the treatment of allergic airway inflammation and airway hyperresponsiveness using a murine model of asthma.

Methods: We investigated the effect of a novel RXR partial agonist (NEt-4IB) on the development of allergic airway inflammation and airway hyperresponsiveness (AHR) in a murine model of asthma. Balb/c mice were sensitized (days 0 and 14) and challenged (days 28-30) with ovalbumin (OVA), and airway inflammation and airway responses were monitored $48 \mathrm{~h}$ after the last OVA challenge. NEt-4IB was administered orally on days 25 to 32.

Results: Oral administration of NEt-4IB significantly suppressed AHR and inflammatory cell accumulation in the airways and attenuated the levels of TNF- $a$ in the lung and IL-5, IL-13 and NO levels in bronchoalveolar lavage (BAL) fluid and the number of periodic acid Schiff (PAS)-positive goblet cells in lung tissue. Treatment with NEt-4IB also significantly suppressed NF-KB expression.

Conclusion: These data suggest that RXRs may be of crucial importance in the mechanism of allergic asthma and that the novel RXR partial agonist NEt-4IB may be a promising candidate for the treatment of allergic airway inflammation and airway hyperresponsiveness in a model of allergic asthma.
\end{abstract}

Keywords: Asthma, RXR, RXR partial agonist, NF-kB, Nitric oxide, Animal model

\section{Background}

Asthma is characterized by chronic airway inflammation and airway hyperresponsiveness (AHR). Airway inflammation results from the influx of activated eosinophils and $\mathrm{T}$ cells at the site of inflammation. T cells, particularly $\mathrm{T}$ helper (Th) type 2 cells, which release IL-4, IL-5, and

\footnotetext{
* Correspondence: akanehir@md.okayama-u.ac.jp

'Department of Hematology, Oncology, Allergy and Respiratory Medicine,

Okayama University Graduate School of Medicine, Dentistry, and

Pharmaceutical Sciences, 2-5-1 Shikata-cho, Kita-ku, Okayama 700-8558,

Japan

Full list of author information is available at the end of the article
}

IL-13, play a pivotal role in the development of AHR and eosinophilic inflammation [1, 2]. However, asthma is a heterogeneous disease with a complex pathophysiology. Current management based on inhaled corticosteroids and long-acting $\beta 2$ agonists is effective in controlling asthma in most patients, but some patients develop severe asthma.

Retinoid X receptors (RXRs) are nuclear receptors that control gene transcription dependent on ligand binding [3] and act as homodimers or heterodimers with peroxisome proliferator-activated receptors (PPARs), liver X 
receptors (LXRs), and other nuclear receptors (NRs) [4-6]. Therefore, RXR agonists have multipotent effects on the mechanism of airway inflammation and may play a critical and powerful role in the treatment of heterogeneous asthma. However, the relative proportions of RXRs interacting as homodimers or heterodimers remain unclear because RXRs are thought to function "permissively" as immune modulators.

RXR agonists are effective in the treatment of several diseases [7]. For example, the RXR full agonist Bexarotene is used for the treatment of cutaneous T cell lymphoma [8] and is also effective against type 2 diabetes, metabolic syndrome [9], Alzheimer's disease [10], and Parkinson's disease in animal models [11]. Kakuta et al. reported that the novel RXR full agonist NEt-TMN is potentially effective to reduce adverse effects while retaining desired activities [12]. However, RXR full agonists, including NEt-TMN and Bexarotene, are associated with strong adverse events, such as weight gain, hepatomegaly, and blood triglyceride elevation, in the treatment of underlying diseases $[12,13]$.

To avoid these severe adverse events, we considered that moderate activation of RXR might be sufficient to regulate allergic inflammation, and we focused on the production of new RXR partial agonists with lower maximum activation of RXR compared to RXR full agonists. The novel RXR partial agonist NEt-4IB has a maximum $55 \%$ RXR efficacy compared with full agonists in a luciferase reporter gene assay, and 28 consecutive days' administration of NEt-4IB resulted in no significant adverse events [14]. Furthermore, we have investigated the pharmacokinetics of NEt-4IB in vivo by positron emission tomography (PET) and revealed an increase in radioactivity in PET imaging of the lung [15].

Other NR superfamily members have been related to allergic inflammation. A PPAR $\gamma$ agonist reduces the response to cockroach allergen challenge in a murine asthma model [16]. An LXR agonist reduces the response to OVA-allergen challenge in a murine model of asthma [17]. NR4A attenuates airway inflammation in a mouse model of asthma [18]. These data suggest that RXRs, which act as both homodimers and heterodimers with other NRs, may be potential targets in the prevention and management of heterogeneous asthma patients. Therefore, we investigated for the first time the effect of the RXR partial agonist NEt-4IB on the development of AHR and eosinophilic airway inflammation in OVA-sensitized and -challenged mice.

\section{Methods}

\section{Animals}

Female BALB/c mice at 8-12 weeks of age were purchased from Charles River Japan, Inc. (Yokohama, Japan). The mice were maintained on an OVA-free diet. All experimental animals used in the present study were housed under a protocol approved by the Institutional Animal Care and Use Committee of Okayama University Medical School (Okayama, Japan).

\section{Sensitization and airway challenge}

The mice were sensitized by intraperitoneal injection of $20 \mu \mathrm{g}$ of OVA (Grade V; Sigma-Aldrich, St Louis, MO, USA) emulsified in $2.25 \mathrm{mg}$ of alum (Inject Alum; Pierce Biotechnology, Rockford, IL, USA) on days 0 and 14. The mice were subsequently challenged with OVA (1\% in saline) by ultrasonic nebulization for $20 \mathrm{~min}$ on days 28, 29, and 30 (OVA/OVA). AHR was assessed $48 \mathrm{~h}$ after the last challenge, and tissues and cells were obtained for further analysis [19]. Control mice were non-sensitized but challenged with OVA (PBS/OVA).

\section{Administration of the novel RXR partial agonist and prednisone}

The mice received the novel RXR partial agonist (NEt-4IB) $(0.0015,0.005$, and $0.015 \%)$ or prednisone (PSL) $(0.005 \%)$ daily on days 25 to 32 orally. The control mice received vehicle.

\section{Determination of airway responsiveness}

A flexiVent small-animal ventilator (SCIREQ, Montreal, $P Q$, Canada) was used to assess airway function (Snapshot) in anesthetized (intraperitoneal injection of sodium pentobarbital, $70 \mathrm{mg} / \mathrm{kg}$ ), mechanically ventilated animals. Changes in lung resistance (RL) were measured in response to increasing doses of inhaled methacholine (MCh) [20]. Airway responsiveness was assessed as the change in airway function (150 breaths/min, tidal volume: $10 \mathrm{ml} / \mathrm{kg}$ ) after challenge with aerosolized $\mathrm{MCh}$ administered for $10 \mathrm{~s}$ (60 breaths/min, tidal volume: $20 \mathrm{ml} / \mathrm{kg})$ at increasing concentrations $(0,1.56,6.25$, 12.5 and $25 \mathrm{mg} / \mathrm{ml}$ ) [21]. Baseline RL values in response to saline at $48 \mathrm{~h}$ were first determined. RL data were continuously collected for up to $3 \mathrm{~min}$, and the maximum values were obtained.

\section{BAL fluid}

After the assessment of AHR, the lungs were lavaged with Hanks' balanced salt solution via the tracheal tube $\left(1 \mathrm{ml} ; 37^{\circ} \mathrm{C}\right)$. The number of cells in the bronchoalveolar lavage (BAL) fluid was determined. Cytospin slides were stained and differentiated in a blinded manner by counting at least 200 cells under light microscopy.

\section{Histological studies of the lung}

Lungs were fixed in $10 \%$ formalin. Blocks of lung tissue were cut around the main bronchus and embedded in paraffin blocks. Lung sections with a thickness of $4 \mu \mathrm{m}$ were stained with hematoxylin-eosin (H\&E) to analyze the difference between eosinophils and neutrophils, and 
periodic acid Schiff (PAS) was used to identify mucuscontaining cells (goblet cells) as previously described [22].

\section{Measurement of cytokines, chemokines and nitric oxide (NO)}

The cytokine levels in the BAL fluid and homogenized lung were measured by ELISA as previously described [23]. All cytokine and chemokine ELISAs (R\&D Systems, Minneapolis, MN, USA) were performed according to the manufacturer's directions. The limits of detection were $5 \mathrm{pg} / \mathrm{ml}$ for IL-4, $0.68 \mathrm{pg} / \mathrm{ml}$ for IL-5, $2 \mathrm{pg} / \mathrm{ml}$ for IL-13, and $0.36 \mathrm{pg} / \mathrm{ml}$ for tumor necrosis factor alpha (TNF- $\alpha)$. For the preparation of lung homogenates, lung tissue was frozen at $-70{ }^{\circ} \mathrm{C}$ immediately after euthanasia. Next, the lung tissue was mixed with a PBS-0.1\% Triton-X100 solution containing proteinase inhibitors at a 1:2.5 ratio of weight per volume (Sigma-Aldrich). The specimens were homogenized and then centrifuged at $14,000 \mathrm{rpm}$ for $30 \mathrm{~min}$. The supernatants were frozen at $-70{ }^{\circ} \mathrm{C}$ until analysis. NO with BAL fluid was measured using a nitrate/nitrite fluorometric assay kit (Cayman chemical, Ann Arbor, MI, USA) as previously described [24].

\section{Cell preparation and culture}

Lung mononuclear cells (MNCs) from OVA-sensitized and -challenged mice were isolated as previously described following collagenase digestion [22]. Lung MNCs were cultured for $24 \mathrm{~h}$ in 96-well round-bottom plates in the presence or absence of OVA $(10 \mu \mathrm{g} / \mathrm{ml})$. Ten days after OVA-sensitization, the spleens were removed from mice and placed in PBS. The tissue was dispersed into single-cell suspensions, and spleen MNCs were purified by Ficoll-Hypaque gradient centrifugation (Sigma-Aldrich). The cells $\left(4 \times 10^{5}\right)$ were then cultured for $48 \mathrm{~h}$ in 96-well round-bottom plates in the presence or absence of OVA $(10 \mu \mathrm{g} / \mathrm{ml})$ and drugs (NEt-4IB or PSL) as previously described [25]. The cytokine levels in the culture supernatants were measured by ELISA.

\section{Measurements of blood parameters}

Triglyceride (TG) levels were measured using a Fuji Dry Chem system (Dry Chem 4000 V; Fuji Medical Co., Tokyo, Japan).

\section{Flow cytometry}

After lung cell purification, intracytoplasmic cytokine staining was performed as previously described [26, 27]. The cells were stained for cell surface markers with PEconjugated anti-CD4 (BD Biosciences, Franklin Lakes, NJ, USA), FITC-conjugated anti-CD8 (BD Biosciences), or APC-conjugated anti-CD3 (BD Biosciences) and then analyzed using a MACS Quant flow cytometer (Miltenyi
Biotec, Auburn, CA, USA) with FlowJo software (TreeStar, Ashland, OR, USA). The numbers of cytokine-producing $\mathrm{CD}^{+}{ }^{+}$or $\mathrm{CD}^{+}{ }^{+} \mathrm{T}$ cells per lung were calculated from the percentages of cytokine-producing cells and the numbers of $\mathrm{CD}^{+}$or $\mathrm{CD}^{+} \mathrm{T}$ cells isolated from the lung. The cells were also stained for cell surface markers with APC-conjugated anti-CD11b (BD Biosciences) and FITCconjugated anti-CD11c (BD Biosciences).

\section{Total RNA isolation and quantitative real-time PCR}

The left lung was homogenized, and total RNA was extracted using TRIzol reagent (Invitrogen, Carlsbad, CA, USA), followed by treatment with DNase (Qiagen, Valencia, CA, USA) according to the manufacturer's instructions. Reverse transcription was performed using oligo (dT) primers and Invitrogen Superscript II Reverse Transcriptase (Life Technologies, Grand Island, NY, USA) to obtain cDNA for PCR. Quantitative real-time PCR was performed in a $25-\mu \mathrm{l}$ reaction using FastStart Essential DNA Green Master (Roche, Basel, Switzerland). The primers sequences were as follows: NF- $\mathrm{kB}$, forward, 5CAACAGATGGGCTACACAGAGG-3, and reverse, 5GGAAGACGAGAGAGGCAGACA-3; GAPDH, forward, 5-TATGTCGTGGAGTCTACTGGT-3, and reverse, 5GAGTTGTCATATTTCTCGTGG-3. The relative expression levels of each target were normalized to GAPDH and calculated using the $\Delta \Delta$ cycle threshold method. There were no differences in GAPDH expression among the groups [28].

\section{Immunoblotting}

Protein extracts were prepared from homogenates suspended in PBS-0.1\% Triton-X100 solution containing proteinase inhibitors (BD Biosciences) and centrifuged at $14,000 \mathrm{rpm}$ min at $4{ }^{\circ} \mathrm{C}$. After quantification using the Bio-Rad protein assay (Bio-Rad, Hercules, CA, USA), SDS was added to the supernatant. Aliquots of the supernatant, each containing $30 \mu \mathrm{g}$ of protein, were separated by SDS-PAGE and electrically transferred to nitrocellulose membranes. Nonspecific binding sites were blocked with Tris-buffered saline (TBS) containing 5\% nonfat dry powdered milk (wt/vol) for $1 \mathrm{~h}$ at room temperature. After a brief rinse with TBS containing $0.1 \%$ Tween 20 (TBST), the protein blots were incubated with 1:50,000 diluted antiNF-kB antibody (cat. no. ab32536, Abcam, Cambridge, MA, USA), 1:1000 diluted anti-inducible nitric oxide synthase antibody (cat. no. ab178945, Abcam) and 1:5000 diluted anti- $\beta$-actin (cat. no. ab8227, Abcam) overnight at $4{ }^{\circ} \mathrm{C}$. The secondary antibody was anti-rabbit IgG (horseradish peroxidase-linked, species-specific whole antibodies; GE Healthcare, Buckinghamshire, UK), which was used at a 1:5000 dilution. 


\section{Statistical analysis}

All results are expressed as the mean \pm standard error of the mean (SEM). ANOVA was used to determine the levels of difference among all groups. Pairs of groups of samples distributed parametrically were compared by unpaired two-tailed Student's $t$-test, and those samples distributed nonparametrically were compared by the Mann-Whitney $U$ test. Significance was assumed at $P$ values $<0.05$.

\section{Results}

Treatment with a novel RXR partial agonist attenuates AHR and airway inflammation in OVA-sensitized and -challenged mice

We assessed the AHR of OVA-sensitized and -challenged mice treated with vehicle (OVA/OVA/vehicle) to increasing doses of inhaled MCh. OVA/OVA/vehicle mice developed AHR compared with the non-sensitized but OVAchallenged mice treated with vehicle (PBS/OVA/vehicle). The administration of the novel RXR partial agonist (NEt-4IB) significantly attenuated the increase in AHR throughout the MCh dose-response curve in a dosedependent manner (Table 1, Fig. 1A) and prevented the increase in the number of lymphocytes and eosinophils in the BAL fluid compared with OVA/OVA/vehicle mice (Fig. 1B).

\section{Effects of prednisone on airway inflammation and hyperresponsiveness in OVA-sensitized and -challenged mice}

PSL-treated mice exhibited a reduced number of macrophages and eosinophils in the BAL fluid compared to OVA/OVA/vehicle mice and OVA/OVA/NEt-4IB mice (Fig. 1B). The administration of PSL significantly attenuated the increase in AHR; however, interestingly, no significant difference was observed between OVA/OVA/PSL mice and OVA/OVA/NEt-4IB mice (Table 1).

\section{Localization of inflammatory cells and mucus production in lung tissue}

The development of AHR is associated with inflammatory changes in lung tissue [23]. To determine if treatment with NEt-4IB affected inflammatory changes in the lung, we assessed tissue inflammation. Hematoxylin-eosinstained lung tissue revealed significant increases in inflammatory cells in peribronchial inflammation in OVA/OVA/ vehicle mice compared with PBS/OVA/vehicle mice. Mice treated with NEt-4IB exhibited reduced numbers of eosinophils and lymphocytes in lung tissue (Fig. 1C). Lung sections were stained with PAS to identify mucus-containing cells in the airway epithelium. A significant increase in PAS-positive goblet cell hyperplasia was observed in OVA/OVA/vehicle mice. Treatment with NEt-4IB significantly reduced the number of PAS-positive cells per millimeter of basement membrane (Fig. 1D).

\section{Treatment with NEt-4IB suppresses IL-5, IL-13 and NO} levels in BAL fluid and TNF- $a$ and iNOS in the lung Cytokine levels in BAL fluid and the lung were measured by ELISA. Treatment with vehicle resulted in significant increases in the levels of Th2 cytokines in BAL fluid and TNF- $\alpha$ in the lung. By contrast, treatment with NEt-4IB significantly reduced not only IL-5 and IL-13 levels but also TNF- $\alpha$ levels compared with vehicletreated OVA/OVA mice (Fig. 1E a-d). IFN- $\gamma$ was not detected even in OVA/OVA/vehicle mice in this study (data not shown).

In asthmatic patients, the level of nitric oxide, which is produced endogenously in the lung by nitric oxide synthase to elicit multiple physiological functions, can be measured in exhaled breath [29]. However, a deficiency in inducible nitric oxide synthase (iNOS) suppresses ozone-induced airway tissue injury and LPS-induced acute airway inflammation in mice [30,31]. NO inhibitors block eosinophil recruitment in the lungs [32]. NO is also a potent vasodilator in the bronchial circulation and may play a major role in airway circulation [33]. In the present study, the level of $\mathrm{NO}$ in the BAL fluid was significantly suppressed in OVA/OVA NEt-4IB-treated mice compared with OVA/OVA vehicle-treated mice (Fig. 1E e), although a significant difference was not recognized among three groups in the expression levels of iNOS in the lung (Fig. 1E f).

Table 1 Dose-dependent effects of NEt-4IB and PSL on AHR

\begin{tabular}{|c|c|c|c|c|c|}
\hline Methacholine $(\mathrm{mg} / \mathrm{mL})$ & 0 & 1 & 6 & 12 & 25 \\
\hline PBS/OVANehicle & $0.93 \pm 0.19$ & $1.57 \pm 0.15$ & $2.22 \pm 0.20$ & $2.93 \pm 0.3 .3$ & $3.95 \pm 0.53$ \\
\hline OVA/OVANehicle & $1.19 \pm 0.26$ & $2.63 \pm 0.51$ & $5.31 \pm 0.52^{*}$ & $7.25 \pm 0.45^{*}$ & $11.27 \pm 0.87^{*}$ \\
\hline OVA/OVA/NEt-4IB 0.0015\% & $0.82 \pm 0.05$ & $2.14 \pm 0.31$ & $4.26 \pm 0.59$ & $5.81 \pm 0.73$ & $9.93 \pm 1.66$ \\
\hline OVA/OVA/NEt-4IB 0.005\% & $0.84 \pm 0.10$ & $1.66 \pm 0.20$ & $3.97 \pm 0.44$ & $6.07 \pm 0.41$ & $8.75 \pm 0.56$ \\
\hline OVA/OVA/NEt-4IB 0.015\% & $1.00 \pm 0.15$ & $2.10 \pm 0.25$ & $3.57 \pm 0.52$ & $5.28 \pm 0.37^{* *}$ & $7.14 \pm 0.31^{* *}$ \\
\hline OVA/OVA/PSL 0.005\% & $0.89 \pm 0.06$ & $1.52 \pm 0.10$ & $3.13 \pm 0.34^{* *}$ & $4.73 \pm 0.47^{* *}$ & $6.38 \pm 0.42^{* *}$ \\
\hline
\end{tabular}

The results for each group are expressed as the mean $\mathrm{RL} \pm \mathrm{SEM}\left(\mathrm{cmH}_{2} \mathrm{O} \mathrm{s} / \mathrm{ml}\right)\left(n=8-12\right.$ in each group). ${ }^{*}$ Significant difference $(P<0.05)$ between PBS/OVA/Vehicle and OVA/OVA/Vehicle. ${ }^{*}$ Significant difference $(P<0.05)$ between OVA/OVA/Vehicle and OVA/OVA/NEt-4IB or OVA/OVA/PSL 
a

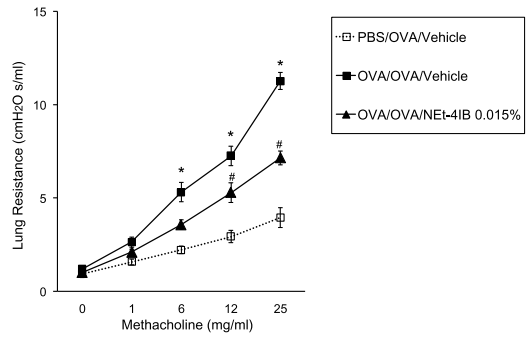

C

(a)

(b)

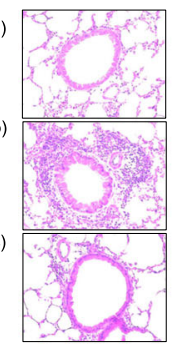

(d)

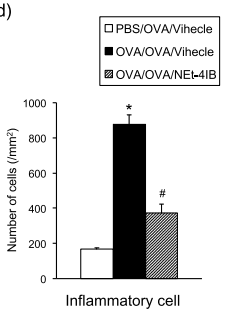

b

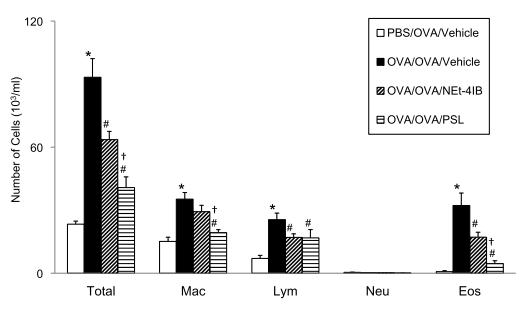

d

(a)

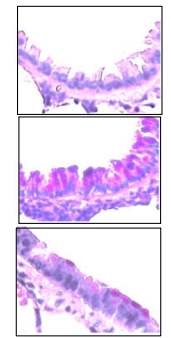

(d)

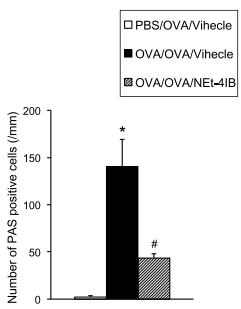

f

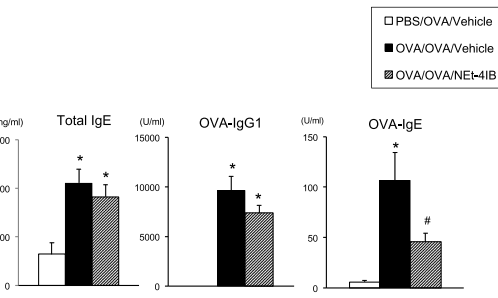

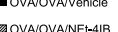

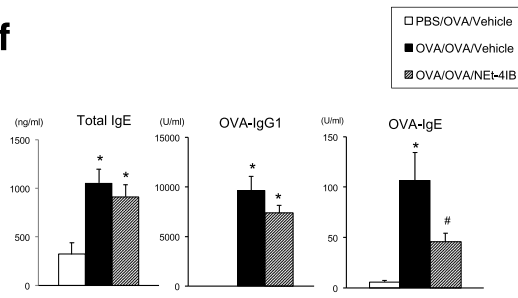

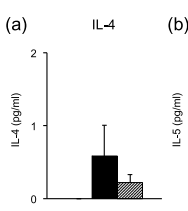

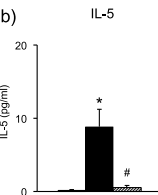

(c)
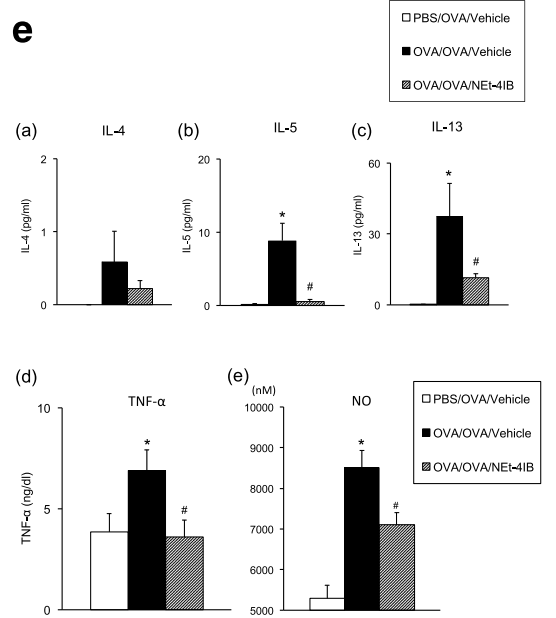

(f)

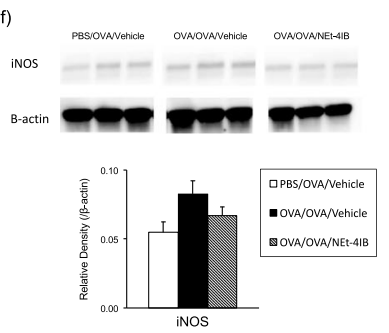

Fig. 1 Treatment with NEt-4IB and PSL attenuates AHR and airway inflammation. a AHR. b Cell composition in BAL fluid. c H\&E-stained lung tissue (final magnification: $\times 400$ ). (a) PBS/OVANehicle, (b) OVA/OVANehicle, (c) OVA/OVA/NEt-4IB, (d) inflammatory cell numbers in the peribronchial and perivascular tissue. $\mathbf{d}$ Treatment with NEt-4IB suppresses goblet cell metaplasia (final magnification: $\times 1000)$. (a) PBS/OVANehicle, (b) OVA/ OVANehicle, (c) OVA/OVA/NEt-4IB, (d) the number of mucus-positive cells. e (a) IL-4, (b) IL-5, (c) IL-13 in BAL fluid, (d) TNF-a in the lung, (e) NO in BAL fluid. $n=8-20$ in each group. ( $f$ ) The expression levels of iNOS in the lung were determined by Western blotting as described in the Methods. $n=4$ in each group. $\mathbf{f}$ Serum levels of (a) total $\operatorname{lgE}$, (b) anti-OVA IgG1, (c) anti-OVA IgE. $n=8-20$ in each group. The results for each group are expressed as the mean \pm SEM. Mac macrophage, Eos eosinophil, Lym lymphocyte, and Neu neutrophil. * Significant differences $(P<0.05)$ between PBS/OVANehicle and OVA/OVANehicle. \# Significant differences $(P<0.05)$ between OVA/OVAVehicle and OVA/OVA/NEt-4IB. + Significant difference $(P<0.05)$ between OVAVOVA/NEt-4IB and OVANOVA/PSL 
Treatment with the RXR partial agonist suppresses serum anti-OVA IgE antibody levels

The serum Ig levels in OVA/OVA/vehicle mice were elevated compared with those in PBS/OVA/vehicle mice, and treatment with NEt-4IB significantly suppressed OVA-specific IgE compared with OVA/OVA/vehicle mice (Fig. 1F).

The numbers of $\mathrm{CD} 4^{+} \mathrm{T}$ cells, $\mathrm{CD} 8^{+} \mathrm{T}$ cells, $\mathrm{CD} 11 \mathrm{~b}^{+}$cells, and $\mathrm{CD} 11 \mathrm{c}^{+}$cells in the lung

To determine if the accumulation of $\mathrm{T}$ cells in the airways of sensitized and challenged mice was affected by treatment with NEt-4IB, lung cells were isolated, and the numbers of both $\mathrm{CD}^{+}$and $\mathrm{CD}^{+} \mathrm{T}$ cells were determined by flow cytometry. The numbers of $\mathrm{CD}^{+}$ and $\mathrm{CD}^{+} \mathrm{T}$ cells were significantly lower in the lungs of NEt-4IB-treated mice compared to vehicle-treated mice (Fig. 2a, b). These data indicate that treatment with NEt4IB attenuated the accumulation of $\mathrm{CD}^{+}$and $\mathrm{CD}^{+} \mathrm{T}$ cells in the airways of OVA-sensitized mice after challenge. The numbers of $\mathrm{CD}_{11} \mathrm{~b}^{+}$cells but not $\mathrm{CD} 11 \mathrm{c}^{+}$cells were significantly lower in the lungs of NEt-4IB-treated mice compared to vehicle-treated mice (Fig. 2c, d).

\section{Cytokine production by lung and spleen MNCs in vitro}

We assessed cytokine production from lung MNCs

(Fig. 3A, B) and spleen MNCs (Fig. 3C, D) in vitro. Lung
MNCs were isolated from OVA-sensitized and -challenged and vehicle mice (OVA/OVA/vehicle). Re-stimulation with OVA $(10 \mu \mathrm{g} / \mathrm{ml})$ for $24 \mathrm{~h}$ significantly increased Th2 cytokine levels in the lung MNC culture supernatants. However, in NEt-4IB-treated mice (OVA/OVA/NEt-4IB), both IL-5 and IL-13 levels were significantly suppressed in OVA-re-stimulated culture supernatants (Fig. 3B a-c). Next, spleen MNCs isolated 10 days after OVA sensitization in mice were stimulated with OVA $(10 \mu \mathrm{g} /$ $\mathrm{ml}$ ) for $48 \mathrm{~h}$ in the presence or absence of NEt-4IB or PSL in vitro. The levels of Th2 cytokines were significantly increased in the culture supernatants from spleen MNCs after culture with OVA. Treatment with NEt-4IB $(10 \mu \mathrm{M})$ significantly decreased the levels of IL-5 and IL-13 in the culture supernatants compared with the non-treated group in vitro. PSL $(1 \mu \mathrm{M})$ had a significant effect on cytokine levels (Fig. 3D a-c).

\section{Triglyceride value in the blood}

To assess adverse events associated with NEt-4IB, we measured serum TG levels, which were $331.3 \pm 13.9$, $332.1 \pm 30.9$, and $367.7 \pm 48.5 \mathrm{ml} / \mathrm{dL}$ in $\mathrm{PBS} / \mathrm{OVA} /$ vehicle, OVA/OVA/vehicle and OVA/OVA/NEt-4IB mice, respectively. There were no significant differences between OVA/OVA/vehicle mice and OVA/OVA/ NEt-4IB mice. Additionally, there were no significant differences in liver size between the two groups (data not shown).
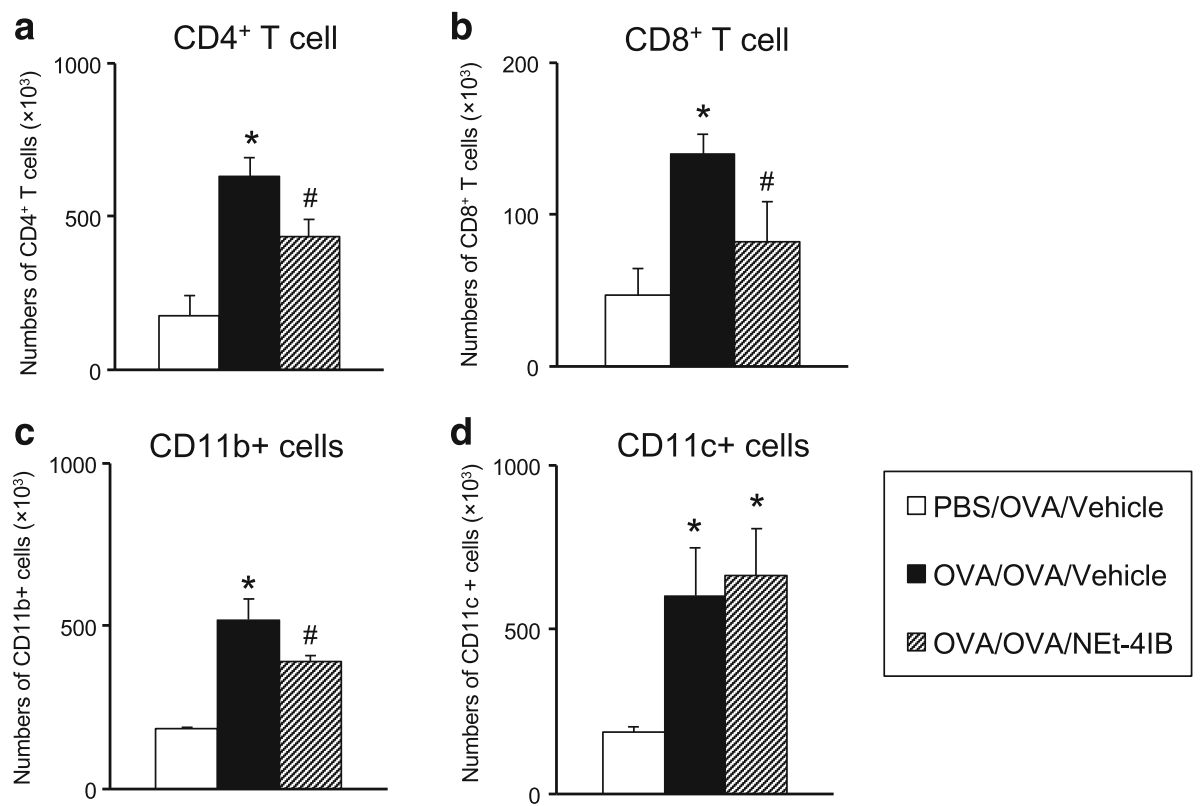

Fig. 2 Numbers of $C D 4^{+}, C D 8^{+} T$ cells and $C D 11 b^{+}, C D 11 c^{+}$cells in the lung. The numbers of $\mathbf{a} C D 4^{+}, \mathbf{b} C D 8^{+} T$ cells, $\mathbf{c} C D 11 b^{+}$cells, and d CD11 $\mathrm{c}^{+}$cells in the lung were calculated as described in the Methods section. $n=8-12$ in each group. The results for each group are expressed as the mean \pm SEM. * Significant differences $(P<0.05)$ between PBS/OVAVehicle and OVA/OVANehicle. \# Significant differences $(P<0.05)$ between OVA/OVANehicle and OVA/OVA/NEt-4IB 
a

Animals: female BALB/c mice $8-12 \mathrm{~W}$

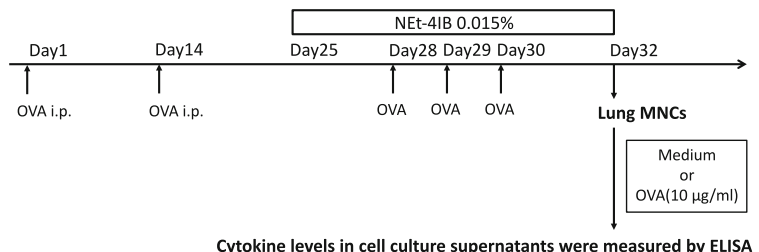

Cytokine levels in cell culture supernatants were measured by ELISA

$\begin{array}{ll}\text { i) } & P B S / O V A / v e h i c l e \\ \text { Group ii) OVA/OVA/vehicle }\end{array}$

iii) OVA/OVA/NEt-4IB $0.015 \%$

b
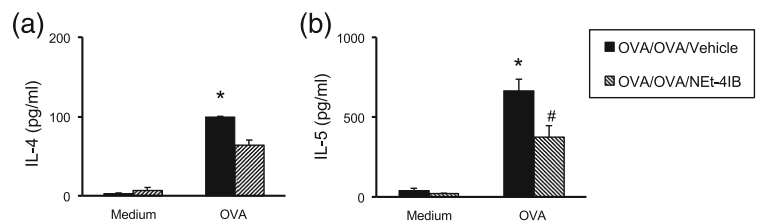

(c)

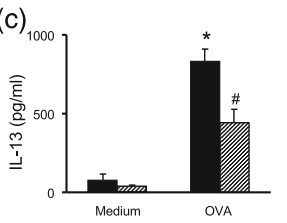

C

Animals: female BALB/c mice $8-12 \mathrm{~W}$

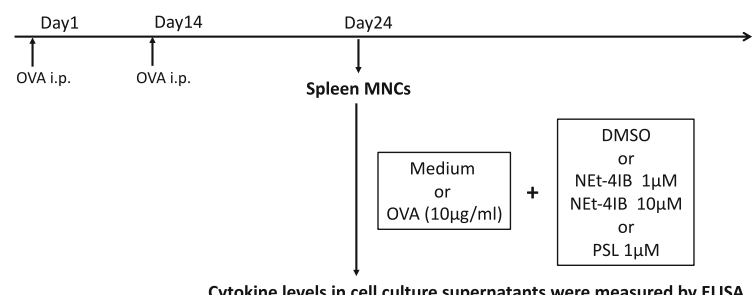

Cytokine levels in cell culture supernatants were measured by ELISA

d

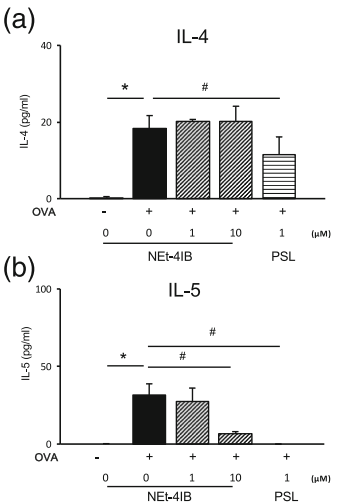

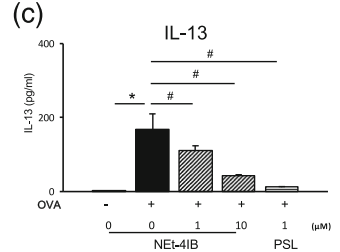

Fig. 3 IL-4, IL-5, and IL-13 levels in culture supernatants from lung and spleen MNCs. a Experimental protocol. Lung mononuclear cells (MNCs) were isolated from OVA-sensitized and -challenged mice and were cultured for $24 \mathrm{~h}$ in the presence or absence of OVA (10 $\mu \mathrm{g} / \mathrm{ml})$ as previously described in the Methods [22]. b (a) IL-4, (b) IL-5, and (c) IL-13 levels in supernatants from cultured lung MNCs isolated from OVA-sensitized and -challenged mice in the presence or absence of OVA $(10 \mu \mathrm{g} / \mathrm{ml})$ were determined by ELISA. c Experimental protocol. Spleen MNCs were isolated from OVA-sensitized mice and were stimulated with OVA for $48 \mathrm{~h}$ in the presence or absence of NEt-4IB $(1,10 \mu \mathrm{M})$ or prednisone $(1 \mu \mathrm{M})$ as previously described in the Methods [25]. $\mathbf{d}(a) \mathrm{IL}-4,(b) \mathrm{IL}-5$, and (c) IL-13 levels in supernatants from cultured spleen MNCs isolated from OVA-sensitized mice in the presence or absence of OVA $(10 \mu \mathrm{g} / \mathrm{ml})$ and NEt-4IB $(1,10 \mu \mathrm{M})$ or PSL $(1 \mu \mathrm{M})$ were determined by ELISA. $n=8-12$ in each group. The results for each group are expressed as the mean \pm SEM. * Significant differences $(P<0.05)$ between medium-stimulated OVA/OVANehicle and OVA-stimulated OVA/OVAVehicle. \# Significant differences between OVA-stimulated OVA/OVAVehicle and OVA/OVA/NEt-4IB or OVAVOVA/PSL

\section{Treatment with NEt-4IB suppresses NF-KB expression in the lung tissues}

$\mathrm{NF}-\mathrm{kB}$ is a transcription factor that acts as a key regulator of immune and inflammatory genes, and activation of the NF- $\mathrm{KB}$ pathway has been implicated in asthma in both experimental models and humans [34, 35]. The NF- $\mathrm{kB}$ mRNA and protein levels were significantly increased in OVA/OVA vehicle-treated mice compared to PBS/OVA mice. Treatment with this partial agonist significantly attenuated the levels of NF- $\mathrm{kB}$ compared with OVA/OVA vehicle-treated mice (Fig. 4).

\section{Discussion}

RXRs function not only as homodimers but also as permissive heterodimers with other NR superfamily members, including VDR, PPAR, and LXR. Therefore, an RXR agonist may exert potential effects on both RXRs and PPAR/RXR or LXR/RXR. A PPAR $\gamma$ agonist ameliorates experimental autoimmune encephalomyelitis or human central nerve system demyelinating diseases in animal models [36]. Additionally, agonists of PPAR $\gamma, \mathrm{LXR}$, and NR4A have some effects on allergic inflammation [16-18]. However, the role of RXR in mouse models of asthma remains unclear.

RXR full agonists are reported to be effective in the treatment of several diseases. In particular, in humans, Bexarotene is used for the treatment of cutaneous T-cell lymphoma [8, 37]. However, RXR full agonists are associated with strong adverse events, including the elevation of blood triglycerides, hepatomegaly and hypothyroidism $[12,13]$. Accordingly, we developed a novel RXR partial agonist that displays no significant adverse events even with 28 consecutive days' administration compared with full agonists [14]. In this study, elevations of TG levels and liver size were not recognized in OVA/OVA/NEt-4IB mice compared with OVA/OVA/vehicle mice. These data suggest that treatment with NEt-4IB in allergic inflammation is effective without severe adverse events. 
a
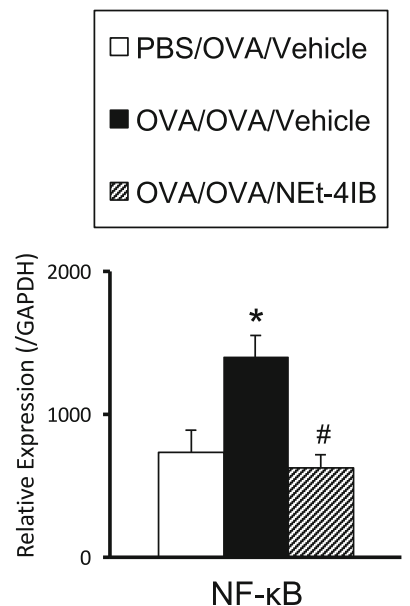

b

PBS/OVAVEhicle OVA/OVA/Vehicle OVA/OVA/NEt-4IB

NF-KB

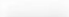

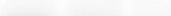

\section{OVAOVANETHB}
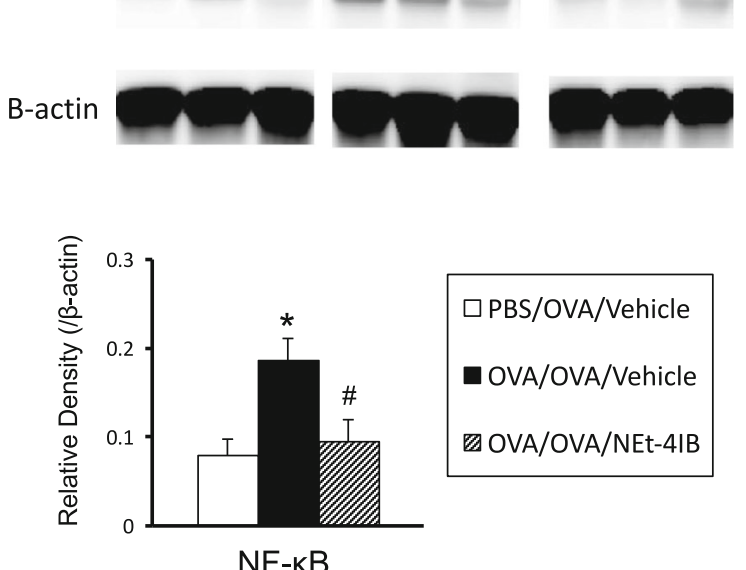

NF-kB

Fig. 4 Treatment with NEt-4IB suppresses NF-KB expression in the lung. The expression levels of NF-kB were determined by RT-PCR (a) and Western blotting $(\mathbf{b})$ as described in the Methods. $n=4$ in each group * Significant differences $(P<0.05)$ between PBS/OVA/Vehicle and OVA/OVA/Vehicle. \# Significant differences $(P<0.05)$ between OVA/OVA/Vehicle and OVA/OVA/NEt-4IB

In the present study, we demonstrated for the first time the potential of our novel RXR selective partial agonist NEt-4IB to present AHR and airway inflammation. Our results clearly show that AHR was significantly suppressed in NEt-4IB-treated mice in a dose-dependent manner, with attenuation of not only eosinophilic airway inflammation and $\mathrm{Th} 2$ cytokine production in the BAL fluid and goblet cell metaplasia in the lung but also TNF- $\alpha$ levels in the lung. These data also suggest that RXR plays critical roles in allergen-induced allergic inflammation.

We previously demonstrated that both $\mathrm{CD}^{+} \mathrm{T}$ cells and $\mathrm{CD}^{+} \mathrm{T}$ cells play pivotal roles in the development of AHR and airway inflammation [26]. In our study, treatment with NEt-4IB significantly decreased the number of $\mathrm{CD}^{+} \mathrm{T}$ cells as well as $\mathrm{CD} 4^{+} \mathrm{T}$ cells compared with vehicle-treated mice. Furthermore, the numbers of $\mathrm{CD}_{11} \mathrm{~b}^{+}$cells which are recognized as monocytes/ macrophages and to a lower extent on granulocytes, NK cells, and a subset of dendritic cells in the lung were significantly lower in NEt-4IB treated mice.

To assess the mechanism of NEt-4IB, we performed in vitro experiments. The levels of IL- 5 and IL-13 in the culture supernatant in OVA-re-stimulated lung MNCs isolated from OVA-sensitized and -challenged mice were significantly suppressed in OVA/OVA/NEt-4IB mice compared with OVA/OVA/vehicle mice. IL-5 and IL-13 levels in the OVA-re-stimulated spleen MNCs isolated from OVA-sensitized mice were significantly increased, and treatment with NEt-4IB in vitro also significantly attenuated the production of IL- 5 and IL-13 in the culture supernatants in a dose-dependent manner. Moreover, there was no significant difference in Th2 cytokine production between the NEt-4IB $(10 \mu \mathrm{M})$-treatment group and PSL $(1 \mu \mathrm{M})$-treatment group. These results suggest that treatment with NEt-4IB suppresses Th2 cytokines both in the sensitization phase and effector phase and may be effective in regulating Th2-related allergic inflammation.

TNF- $\alpha$ is a pro-inflammatory Th1 cytokine that induces airway inflammation and hyperresponsiveness, mucus hypersecretion, and the activation of macrophages. In two small, placebo-controlled, double-blind, crossover studies of patients with corticosteroid refractory asthma, treatment with anti-TNF- $\alpha$ antibody (etanercept) resulted in clinical improvement in PC20, quality-of-life scores, and lung function [38] and improvement in asthma control questionnaire scores with reductions in the use of nebulized $\beta 2$ agonists [39]. However, in a subsequent larger study in uncontrolled severe asthma, the anti-TNF- $\alpha$ antibody had no overall beneficial effects and increased the risk of serious side effects, although a post-hoc analysis suggested that patients with substantial bronchodilator reversibility had fewer exacerbations $[40,41]$. These data may indicate the importance of TNF- $\alpha$ in the innate immune responses and suggest that complete suppression of TNF- $\alpha$ may be a critical and problematic approach. However, NEt-4IB is a partial RXR agonist, and treatment with NEt-4IB significantly suppressed TNF- $\alpha$ levels in the lung compared with vehicle-treated OVA/OVA mice in this study.

TNF- $\alpha$ triggers the activation of the inhibitor kappa- $\mathrm{B}$ (IкB) kinase (IKK)/NF- $\mathrm{kB}$ and mitogen-activated protein kinase (MAPK)/AP-1 pathways [42], and NF- $\mathrm{BB}$ translocation from the cytoplasm to the nucleus and binding 
to the promoter modulate the expression of inflammatory genes, including iNOS, inflammatory cytokines and chemokines. Additionally, several studies have reported that the activation of the NF- $\mathrm{KB}$ pathway is involved in both experimental murine asthma models and human asthmatics [34, 35]. Furthermore, iNOS produces nitric oxide (NO), which acts as a toxic radical and can cause tissue and cell damage. The over-production of NO may recruit eosinophils into the airway, resulting in the aggravation of airway inflammation [43]. $\mathrm{Na}$ et al. reported that RXR may directly modulate NF-kB-DNA interactions by forming a complex with NF- $\mathrm{kB}$ that cannot bind to $\kappa B$ sites [44]. In the present study, treatment with NEt-4IB significantly reduced NO levels in BAL fluid as well as TNF- $\alpha$ in lung homogenates compared with OVA/OVA vehicle-treated mice. These data suggest that NEt-4IB may affect eosinophilic inflammation by decreasing $\mathrm{NO}$ via the TNF- $\alpha / \mathrm{NF}-\mathrm{kB}$ pathway or directly interacting with NF-kB.

\section{Conclusion}

These findings indicate the therapeutic potential of the novel RXR partial agonist NEt-4IB in the development of allergic airway inflammation and AHR. Although additional studies will be required to demonstrate that NEt-4IB may partially and permissively effect heterodimeric partners such as PPARs, NEt-4IB may be a promising candidate for the treatment of allergic airway inflammation and airway hyperresponsiveness in Th2 high allergic asthma.

\footnotetext{
Abbreviations

AHR: Airway hyperresponsiveness; BAL: Bronchoalveolar lavage;

iNOS: Inducible nitric oxide synthase; MCh: Methacholine; NO: Nitric oxide; NR: Nuclear receptor; OVA: Ovalbumin; RXR: Retinoid X receptor

\section{Acknowledgements}

"Not applicable" in this section.

\section{Funding}

This study is supported in part by a grant from the Ministry of Education, Science, and Culture of Japan (A.K.).

This study is supported in part by the Translational Research Network Program from Japan Agency for Medical Research and Development, AMED (H.K.).
}

\section{Availability of data and materials}

Data sharing not applicable to this article as no datasets were generated or analysed during the current study.

\section{Authors' contributions}

AK conceived the design of this study and supervised the scientific work. UF, NM, NO, DM, AT, EM, HN. KW, HK and MK performed experiments. AK, UF and MT analysed the data. All authors contributed and approved the full manuscript.

\section{Competing interests}

The authors declare that they have no competing interests.

\section{Consent for publication}

"Not applicable" in this section.
Ethics approval and consent to participate

All experimental animals used in the present study were housed under a protocol approved by the Institutional Animal Care and Use Committee of Okayama University Medical School (Okayama, Japan).

\section{Author details}

'Department of Hematology, Oncology, Allergy and Respiratory Medicine, Okayama University Graduate School of Medicine, Dentistry, and Pharmaceutical Sciences, 2-5-1 Shikata-cho, Kita-ku, Okayama 700-8558, Japan. ${ }^{2}$ Division of Pharmaceutical Sciences, Okayama University Graduate School of Medicine, Dentistry, and Pharmaceutical Sciences, 1-1-1

Tsushima-naka, Kita-ku, Okayama 700-8530, Japan.

Received: 25 October 2016 Accepted: 13 January 2017

Published online: 23 January 2017

\section{References}

1. Busse WW, Lemanske Jr RF. Asthma. N Engl J Med. 2001;344:350-62.

2. Lee NA, Gelfand EW, Lee JJ. Pulmonary T cells and eosinophils: coconspirators or independent triggers of allergic respiratory pathology? J Allergy Clin Immunol. 2001;107:945-57.

3. Germain P, Chambon P, Eichele G, Evans RM, Lazar MA, Leid M, De Lera AR, Lotan R, Mangelsdorf DJ, Gronemeyer H. International Union of Pharmacology. LXIII. Retinoid X receptors. Pharmacol Rev. 2006:58:760-72.

4. Mangelsdorf DJ, Thummel C, Beato M, Herrlich P, Schutz G, Umesono K, Blumberg B, Kastner P, Mark M, Chambon P, Evans RM. The nuclear receptor superfamily: the second decade. Cell. 1995;83:835-9.

5. Shulman Al, Larson C, Mangelsdorf DJ, Ranganathan R. Structural determinants of allosteric ligand activation in RXR heterodimers. Cell. 2004;116:417-29.

6. Evans RM, Mangelsdorf DJ. Nuclear receptors, RXR, and the big bang. Cell. 2014;157:255-66.

7. Altucci L, Leibowitz MD, Ogilvie KM, de Lera AR, Gronemeyer H. RAR and RXR modulation in cancer and metabolic disease. Nat Rev Drug Discov. 2007;6:793-810.

8. Pileri A, Delfino C, Grandi V, Pimpinelli N. Role of bexarotene in the treatment of cutaneous T-cell lymphoma: the clinical and immunological sides. Immunotherapy. 2013;5:427-33.

9. Mukherjee R, Davies PJ, Crombie DL, Bischoff ED, Cesario RM, Jow L, Hamann LG, Boehm MF, Mondon CE, Nadzan AM, et al. Sensitization of diabetic and obese mice to insulin by retinoid $\mathrm{X}$ receptor agonists. Nature. 1997;386:407-10.

10. Cramer PE, Cirrito JR, Wesson DW, Lee CY, Karlo JC, Zinn AE, Casali BT, Restivo JL, Goebel WD, James MJ, et al. ApoE-directed therapeutics rapidly clear beta-amyloid and reverse deficits in AD mouse models. Science. 2012;335:1503-6.

11. McFarland K, Spalding TA, Hubbard D, Ma JN, Olsson R, Burstein ES. Low dose bexarotene treatment rescues dopamine neurons and restores behavioral function in models of Parkinson's disease. ACS Chem Neurosci. 2013:4:1430-8.

12. Kakuta H, Ohsawa F, Yamada S, Makishima M, Tai A, Yasui H, Yoshikawa Y. Feasibility of structural modification of retinoid $X$ receptor agonists to separate blood glucose-lowering action from adverse effects: studies in KKA(y) type 2 diabetes model mice. Biol Pharm Bull. 2012:35:629-33.

13. Duvic M, Martin AG, Kim Y, Olsen E, Wood GS, Crowley CA, Yocum RC. Phase 2 and 3 clinical trial of oral bexarotene (Targretin capsules) for the treatment of refractory or persistent early-stage cutaneous T-cell lymphoma. Arch Dermatol. 2001;137:581-93.

14. Kawata K, Morishita K, Nakayama M, Yamada S, Kobayashi T, Furusawa Y, Arimoto-Kobayashi S, Oohashi T, Makishima M, Naitou H, et al. RXR partial agonist produced by side chain repositioning of alkoxy RXR full agonist retains antitype 2 diabetes activity without the adverse effects. J Med Chem 2015;58:912-26.

15. Kobayashi T, Furusawa Y, Yamada S, Akehi M, Takenaka F, Sasaki T, Akahoshi A, Hanada T, Matsuura E, Hirano H, et al. Positron emission tomography to elucidate pharmacokinetic differences of regioisomeric retinoid $x$ receptor agonists. ACS Med Chem Lett. 2015;6:334-8.

16. Narala VR, Ranga R, Smith MR, Berlin AA, Standiford TJ, Lukacs NW, Reddy RC. Pioglitazone is as effective as dexamethasone in a cockroach allergen-induced murine model of asthma. Respir Res. 2007;8:90. 
17. Park SJ, Lee KS, Kim SR, Min KH, Choe YH, Moon H, Chae HJ, Yoo WH, Lee YC Peroxisome proliferator-activated receptor gamma agonist down-regulates IL-17 expression in a murine model of allergic airway inflammation. J Immunol. 2009:183:3259-67.

18. Kurakula K, Vos M, Logiantara A, Roelofs JJ, Nieuwenhuis MA, Koppelman GH, Postma DS, van Rijt LS, de Vries CJ. Nuclear receptor Nur77 attenuates airway inflammation in mice by suppressing NF-kappaB activity in lung epithelial cells. J Immunol. 2015;195:1388-98.

19. Hirano A, Kanehiro A, Ono K, Ito W, Yoshida A, Okada C, Nakashima H, Tanimoto Y, Kataoka M, Gelfand EW, Tanimoto M. Pirfenidone modulates airway responsiveness, inflammation, and remodeling after repeated challenge. Am J Respir Cell Mol Biol. 2006;35:366-77.

20. Lee YM, Miyahara N, Takeda K, Prpich J, Oh A, Balhorn A, Joetham A, Gelfand EW, Dakhama A. IFN-gamma production during initial infection determines the outcome of reinfection with respiratory syncytial virus. Am J Respir Crit Care Med. 2008;177:208-18.

21. Koga H, Miyahara N, Fuchimoto Y, Ikeda G, Waseda K, Ono K, Tanimoto Y, Kataoka M, Gelfand EW, Tanimoto M, Kanehiro A. Inhibition of neutrophil elastase attenuates airway hyperresponsiveness and inflammation in a mouse model of secondary allergen challenge: neutrophil elastase inhibition attenuates allergic airway responses. Respir Res. 2013;14:8.

22. Fuchimoto Y, Kanehiro A, Miyahara N, Koga H, Ikeda G, Waseda K, Tanimoto Y, Ueha S, Kataoka M, Gelfand EW, Tanimoto M. Requirement for chemokine receptor 5 in the development of allergen-induced airway hyperresponsiveness and inflammation. Am J Respir Cell Mol Biol. 2011:45:1248-55.

23. Ito W, Tanimoto M, Ono K, Mizuno S, Yoshida A, Koga H, Fuchimoto Y, Kondo N, Tanimoto Y, Kiura K, et al. Growth factors temporally associate with airway responsiveness and inflammation in allergen-exposed mice. Int Arch Allergy Immunol. 2008;145:324-39.

24. Misko TP, Schilling RJ, Salvemini D, Moore WM, Currie MG. A fluorometric assay for the measurement of nitrite in biological samples. Anal Biochem. 1993;214:11-6

25. Miyahara N, Takeda K, Kodama T, Joetham A, Taube C, Park JW, Miyahara S, Balhorn A, Dakhama A, Gelfand EW. Contribution of antigen-primed CD8+ $T$ cells to the development of airway hyperresponsiveness and inflammation is associated with IL-13. J Immunol. 2004;172:2549-58.

26. Miyahara N, Swanson BJ, Takeda K, Taube C, Miyahara S, Kodama T, Dakhama A, Ott VL, Gelfand EW. Effector CD8+ T cells mediate inflammation and airway hyper-responsiveness. Nat Med. 2004;10:865-9.

27. Nishimori $H$, Maeda $Y$, Teshima T, Sugiyama $H$, Kobayashi $K$, Yamasuji $Y$, Kadohisa S, Uryu H, Takeuchi K, Tanaka T, et al. Synthetic retinoid Am80 ameliorates chronic graft-versus-host disease by down-regulating Th1 and Th17. Blood. 2012;119:285-95.

28. Taniguchi A, Miyahara N, Waseda K, Kurimoto E, Fujii U, Tanimoto Y, Kataoka M, Yamamoto Y, Gelfand EW, Yamamoto H, et al. Contrasting roles for the receptor for advanced glycation end-products on structural cells in allergic airway inflammation vs. airway hyperresponsiveness. Am J Physiol Lung Cell Mol Physiol. 2015;309:L789-800.

29. Calhoun WJ, Ameredes BT, King TS, Icitovic N, Bleecker ER, Castro M Cherniack RM, Chinchilli VM, Craig T, Denlinger L, et al. Comparison of physician-, biomarker-, and symptom-based strategies for adjustment of inhaled corticosteroid therapy in adults with asthma: the BASALT randomized controlled trial. JAMA. 2012;308:987-97.

30. Fakhrzadeh L, Laskin JD, Laskin DL. Deficiency in inducible nitric oxide synthase protects mice from ozone-induced lung inflammation and tissue injury. Am J Respir Cell Mol Biol. 2002;26:413-9.

31. Okamoto T, Gohil K, Finkelstein El, Bove P, Akaike T, van der Vliet A. Multiple contributing roles for NOS2 in LPS-induced acute airway inflammation in mice. Am J Physiol Lung Cell Mol Physiol. 2004;286:L198-209.

32. Beauvais $F$, Michel $L$, Dubertret $L$. The nitric oxide donors, azide and hydroxylamine, inhibit the programmed cell death of cytokine-deprived human eosinophils. FEBS Lett. 1995;361:229-32.

33. Barnes PJ, Liew FY. Nitric oxide and asthmatic inflammation. Immunol Today. 1995;16:128-30

34. Hart LA, Krishnan VL, Adcock IM, Barnes PJ, Chung KF. Activation and localization of transcription factor, nuclear factor-kappaB, in asthma. Am J Respir Crit Care Med. 1998;158:1585-92.

35. Poynter ME, Cloots R, van Woerkom T, Butnor KJ, Vacek P, Taatjes DJ, Irvin CG, Janssen-Heininger YM. NF-kappa B activation in airways modulates allergic inflammation but not hyperresponsiveness. J Immunol. 2004;173:7003-9.
36. Klotz L, Burgdorf S, Dani I, Saijo K, Flossdorf J, Hucke S, Alferink J, Nowak N, Beyer M, Mayer G, et al. The nuclear receptor PPAR gamma selectively inhibits Th17 differentiation in a T cell-intrinsic fashion and suppresses CNS autoimmunity. J Exp Med. 2009:206:2079-89.

37. Gniadecki R, Assaf C, Bagot M, Dummer R, Duvic M, Knobler R, Ranki A, Schwandt P, Whittaker S. The optimal use of bexarotene in cutaneous T-cell lymphoma. Br J Dermatol. 2007;157:433-40.

38. Berry MA, Hargadon B, Shelley M, Parker D, Shaw DE, Green RH, Bradding P, Brightling CE, Wardlaw AJ, Pavord ID. Evidence of a role of tumor necrosis factor alpha in refractory asthma. N Engl J Med. 2006;354:697-708.

39. Morjaria JB, Chauhan AJ, Babu KS, Polosa R, Davies DE, Holgate ST. The role of a soluble TNFalpha receptor fusion protein (etanercept) in corticosteroid refractory asthma: a double blind, randomised, placebo controlled trial. Thorax. 2008;63:584-91.

40. Wenzel SE, Barnes PJ, Bleecker ER, Bousquet J, Busse W, Dahlen SE, Holgate ST, Meyers DA, Rabe KF, Antczak A, et al. A randomized, double-blind, placebocontrolled study of tumor necrosis factor-alpha blockade in severe persistent asthma. Am J Respir Crit Care Med. 2009;179:549-58.

41. Holgate ST, Noonan M, Chanez P, Busse W, Dupont L, Pavord I, Hakulinen A, Paolozzi L, Wajdula J, Zang C, et al. Efficacy and safety of etanercept in moderate-to-severe asthma: a randomised, controlled trial. Eur Respir J. 2011:37:1352-9.

42. Baud V, Karin M. Signal transduction by tumor necrosis factor and its relatives. Trends Cell Biol. 2001;11:372-7.

43. Jeon CM, Shin IS, Shin NR, Hong JM, Kwon OK, Kim HS, Oh SR, Myung PK, Ahn KS. Siegesbeckia glabrescens attenuates allergic airway inflammation in LPS-stimulated RAW 264.7 cells and OVA induced asthma murine model. Int Immunopharmacol. 2014;22:414-9.

44. Na SY, Kang BY, Chung SW, Han SJ, Ma X, Trinchieri G, Im SY, Lee JW, Kim TS Retinoids inhibit interleukin-12 production in macrophages through physical associations of retinoid X receptor and NFkappaB. J Biol Chem. 1999; 274:7674-80.

\section{Submit your next manuscript to BioMed Central and we will help you at every step:}

- We accept pre-submission inquiries

- Our selector tool helps you to find the most relevant journal

- We provide round the clock customer support

- Convenient online submission

- Thorough peer review

- Inclusion in PubMed and all major indexing services

- Maximum visibility for your research

Submit your manuscript at www.biomedcentral.com/submit
) Biomed Central 